\title{
Knowledge, Awareness, and Practice of Different Nerve Blocks for Mandibular Molar Root Canal Treatment
}

\author{
P. Keshaav Krishnaa ${ }^{1}$, Madhulaxmi Marimuthu ${ }^{2}$ \\ ${ }^{1}$ Department of General Dentistry, Saveetha Dental College, Saveetha Institute of Medical and Technical \\ Sciences, Chennai, Tamil Nadu, India. ${ }^{2}$ Department of Oral and Maxillofacial Surgery, Saveetha Dental \\ College, Saveetha Institute of Medical and Technical Sciences, Chennai, Tamil Nadu, India.
}

\section{ABSTRACT}

\section{BACKGROUND}

Root canal treatment is the most commonly performed procedure in dentistry in the field of endodontics. Prior to the procedure local anaesthesia is administered to ensure painless pulp extirpation and cleaning. There are various methods in which this is done by different practitioners, some prefer to administer a nerve block while a few only use an infiltration, and some use both. We wanted to assess the knowledge, awareness, and practice, regarding appropriate anaesthesia to be used while performing root canal therapy for mandibular molar, among practitioners and post graduate students in India.

\section{METHODS}

A total of 80 specialists volunteered to participate in the study. A simple online questionnaire with 10 relevant questions was framed and circulated to the participants. Responses that were received were verified and analysed using SPSS.

\section{RESULTS}

$50 \%$ of the respondents administered a classical inferior alveolar nerve block involving the IAN, lingual and long buccal nerve. $26 \%$ of the respondents anesthetised the inferior alveolar nerve and lingual nerve and $17 \%$ anesthetised the inferior alveolar nerve and long buccal nerve.

\section{CONCLUSIONS}

Anaesthesia of IAN alone should suffice during RCT of the mandibular molars. However, there is no adequate information and knowledge regarding the technique and the amount of local anaesthetic to be delivered for root canal therapy for mandibular molars thus inflicting further pain to the patient.

\section{KEY WORDS}

Local Anaesthesia, Root Canal Treatment, Nerve Block, Endodontics, LA
Corresponding Author: Dr. P. Keshaav Krishnaa, \#163, Poonamallee High Road, Velappananchavadi, Tamil Nadu, India.

E-mail: keshaav.krishnaa.98@gmail.com

DOI: $10.14260 / \mathrm{jemds} / 2020 / 710$

How to Cite This Article:

Krishnaa PK, Marimuthu M. Knowledge, awareness, and practice of different nerve blocks for mandibular molar root canal treatment. J Evolution Med Dent Sci 2020;9(43):3237-3241, DOI: $10.14260 /$ jemds/2020/710

Submission 10-06-2020,

Peer Review 03-09-2020,

Acceptance 10-09-2020,

Published 26-10-2020.

Copyright (C) 2020 JEMDS. This is an open access article distributed under Creative Commons Attribution License [Attribution 4.0 International (CC BY 4.0)] 


\section{BACKGROUND}

Local anaesthetics are the most widely and commonly used drugs in dentistry. Pain and dentistry are often synonymous in the minds of patients, particularly those with poor dentition due to various extractions, periodontal disease requiring surgery or symptomatic teeth requiring endodontic therapy. Dental practitioners, before beginning the procedure, identify a good anaesthetic agent and technique to focus solely on the operative procedures without distractions from pain-induced patient movements. Research has shown that the major fear during a dental procedure is the fear of pain associated with intraoral administration of local anaesthetics, which is the most common method for blocking pain during dental procedures. This is considered aversive due to the pain associated with the injection and the perceived threat of needle puncture prior to the injection. ${ }^{1}$ Another survey finding was that those individuals who reported as highly fearful of dental procedures were worried about receiving oral injections and demonstrated an association between high dental anxieties and missed or / and delayed appointments. ${ }^{2}$ There is no doubt that the most widely used method for pain management during dental, and particularly endodontic, procedures is to administer intraoral local anaesthesia. ${ }^{3}$ Pain management approaches during root canal therapy can be based on one or a combination of such mechanisms. Blocking the nociceptive impulses during root canal treatment is performed with the administration of local anaesthesia ${ }^{4}$ Pain management during and after root canal treatment is a major challenge for dental practitioners.5,6 Various studies of investigations have been performed to overcome pain during and following root canal therapy. ${ }^{7}$ Patient care should always put as the first priority during any clinical procedure. However the correct anaesthetic protocol to be followed for a root canal treatment has not been adequately documented, this further leads to various practices that lead to issues regarding the quality of life of the patient. This is a first of its kind study where the anaesthetic requirement for a root canal treatment is being assessed.

One of the most common procedures that is carried out in the field of Endodontics is root canal treatment and hence appropriate administration of anaesthesia and reducing pain is of utmost importance in the field. The aim of the study is to assess the knowledge awareness and practice of different nerve blocks administered during Mandibular molar root canal treatment.

\section{METHODS}

The questionnaire was sent to 80 participants and all responded. In the present KAP survey, the study population that was included as part of the study included practitioners in the field of endodontics and postgraduates in the field of endodontics as these are the participants who are primarily involved in administering Local Anaesthesia during a root canal treatment on an everyday basis. The study was circulated in the form of an online survey collecting responses from the participants. This is a first of its kind study and thus the questionnaire was unique for the same.
Various questions that were included as part of this study were:

1. Employment Status as an Endodontist.

2. What nerve block do they give for the root canal treatment of a Mandibular Molar?

3. How much ml of LA do they use for a lower molar RCT.?

4. What type of LA do they use?

5. What Branches do they anaesthetise for a lower molar RCT.?

6. In 10 cases of lower molar RCTs, how many cases do they repeat the block.

7. How many cases do they give an Intra pulpal dose of LA as well in about 10 cases?

8. How effective do they think their block is?

9. Do they accompany their block with an infiltration?

In which state of the treatment does the patient experience maximum pain?

\section{RESULTS}

A total of 80 responses was received. The responses were then verified and the results were tabulated. The results were plotted in the forms of graphs and then analysed.

Out of the study population, $39.5 \%$ of the participants were practitioners and $60.5 \%$ of the participants were post graduate students in the field of endodontics. (Fig. 1)
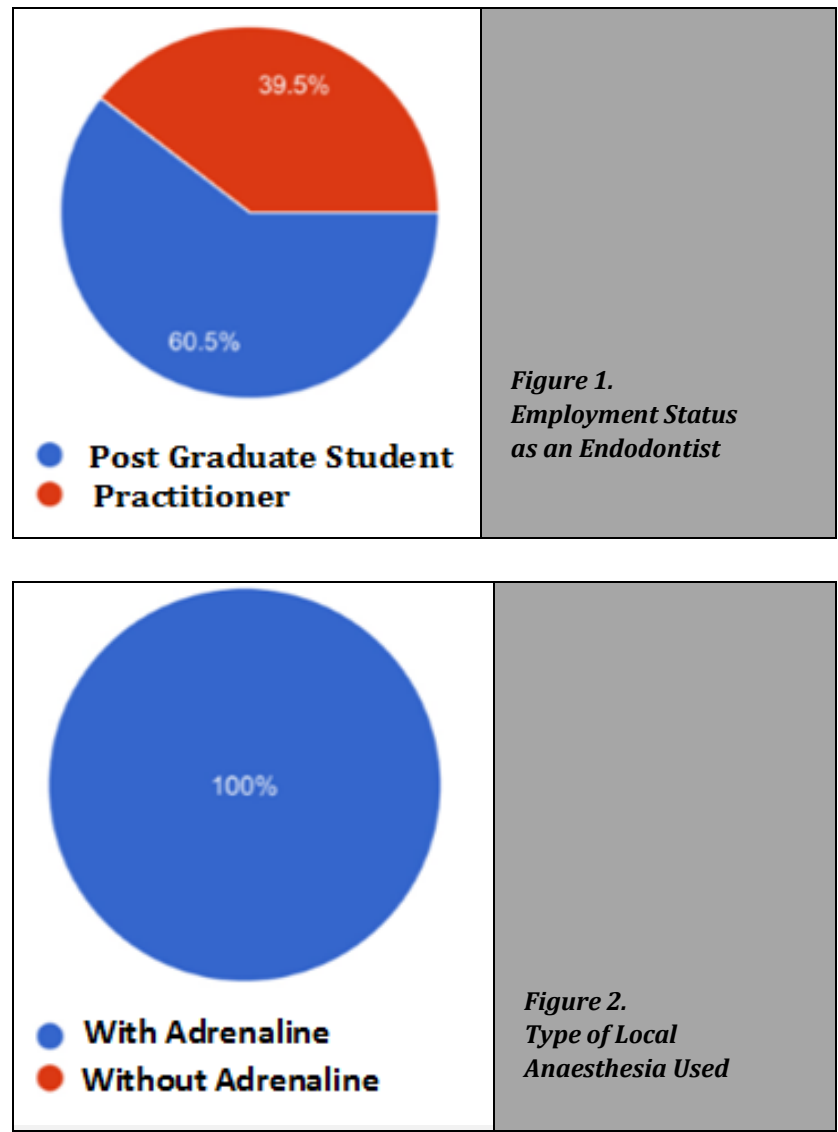

A question was posed as to what nerve block, sdhould they give for a lower molar root canal treatment and the entire study population $(100 \%)$ had opted for classical nerve block, 
none of the study participants opted for Gow Gates or Vazirani technique. The most commonly used type of LA is incorporated along with adrenaline through the responses received as part of the present study as $100 \%$ of the participants opted for using lignocaine along with adrenaline. (Fig. 2)

The question which was later posed to the study population involved the amount of local anaesthetic they would use for a lower molar for a root canal treatment. (Fig. 3) shows that $65.8 \%$ of the population use about $2-3 \mathrm{ml}, 31.6 \%$ of the population use $1-2 \mathrm{ml}$ and the remaining $2.6 \%$ use $3-$ $4 \mathrm{ml}$ of local anaesthetic agent.
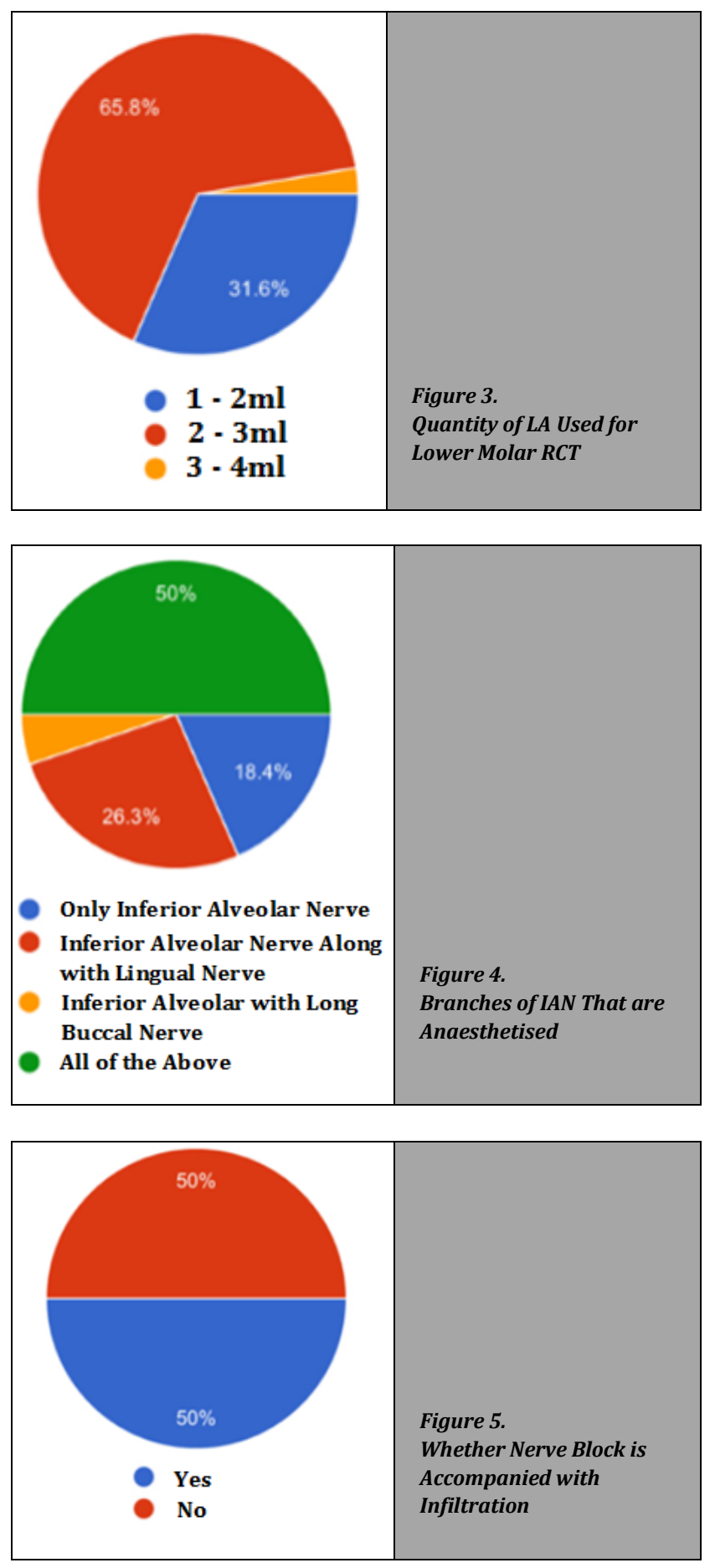

The responses that were established through this question is of high importance. (Fig. 4) $50 \%$ of the population anaesthetise the inferior alveolar nerve along with the long buccal and the lingual nerve. On Probing on the use of an infiltration during the root canal treatment (Fig. 5), $50 \%$ of the population admitted to administering it along with a nerve block.

The participants were then asked in about 10 cases how many they would administer an Intra pulpal dose of local anaesthetic in. (Fig. 6) Majority of the population (34.2\%) have opted that for about 2 cases they would administer an Intra pulpal dose of LA as well.

\section{DISCUSSION}

Local anaesthesia administration is a crucial aspect that is to be considered in patient-care to deliver painless treatment procedures. This is a first of its kind study. In the present study it is observed that for a lower molar root canal treatment practitioners relied more on classical inferior alveolar nerve block that other techniques. This can be attributed to the fact that the method is the most widely taught method of inferior alveolar nerve block administration and the ease of the same. ${ }^{8}$ Although Gow Gates uses a more geometric and mathematical approach based on planes and provides good success rates the same has not been incorporated into clinical practice. ${ }^{9}$ All participants voted that they administer local anaesthetic in combination with adrenaline, The use of adrenaline prolongs the duration and depth of anaesthesia as well as helps to have a better onset of action of the same ${ }^{10}$ and hence it can be considered beneficial that the present study population prefer that over the alternative without adrenaline. But it has to be taken into account that when lignocaine is used along with adrenaline there is a significant change in the blood glucose level that is observed ${ }^{11}$ and adequate precautions have to be taken regarding the same in patients with systemic conditions such as diabetes.

There is no literature that is available that suggests the amount of local anaesthetic agent that is required to be deposited for a lower molar Root canal treatment. Further studies to be done to standardise the same which can be brought into clinical practice. However it has been reported that doubling the amount of LA does not increase the incidence of pulpal anaesthesia with the inferior alveolar nerve block. ${ }^{12}$ Thus in the present day scenario there is a chance of systemic toxicity with unnecessary reasons.

The posterior trunk of the mandibular nerve divides into two branches known as the inferior alveolar nerve and the lingual nerve. The inferior alveolar nerve carries the motor as well as the sensory fibers and travels along the medial aspect of the lateral pterygoid muscle. Prior to entering the mandibular foramen, it gives rise to branches that provide motor innervation to the mylohyoid and anterior belly of digastric muscle which is responsible for elevating the hyoid and complex movements of the jaw (speaking, swallowing, chewing, and breathing). Once the nerve enters the mandibular foramen, it supplies innervation to the mandibular teeth as well as the lower alveolar ridge. A branch of the nerve exits through the mental foramen to become the mental nerve which provides sensory innervation to the dermis of the chin and lower lip and the remaining fibers continue anteriorly to 
provide innervation to the mandibular canines and mandibular incisors. The lingual nerve innervated the anterior two-thirds of the tongue and mucous membrane for sense but does not innervate taste fibers. ${ }^{13,14}$ Thus it is evident that the only nerve supplying the root canal of the lower molar teeth is the inferior alveolar nerve and hence it is unnecessary to deliver LA to the lingual branch and the long buccal branch. But the majority of the population (50\%) deliver LA in all the branches. The pain level that is perceived due to long buccal nerve block is quite high ${ }^{15}$ and hence the need for inflicting pain to the patient is unnecessary. This increases the risk for complications of local anaesthesia 16,17 and unnecessary branches are anaesthetised. In the assessed knowledge it is observed most of the study participants administer an infiltration along with a nerve block. It has been reported that usage of a buccal or lingual infiltration in combination with an inferior alveolar nerve block is not effective and does not produce any difference in the anaesthesia that is achieved by Foster $\mathrm{W}$ et al ${ }^{18}$ This also affects the anxiety that a patient has towards dental treatment. However, on failure of inferior alveolar nerve block the usage of infiltration as an emergency resort has been proven to be effective. ${ }^{19}$ But this should only be used as an emergency measure and not as a standardised practice.

There could be a number of reasons for failure of pulpal anaesthesia using Inferior alveolar nerve block such as altered membrane excitability of peripheral nociceptors ${ }^{20}$ or due to Tetrodotoxin resistant channels which are basically a class of sodium channels that are resistant to the action of the local anaesthetic agent, a related factor is the increased expression of sodium channels in pulp diagnosed with irreversible pulpitis, ${ }^{21}$ psychological factors or due to the most common factor which is hot tooth. There are various strategies to tackle a hot tooth situation and the administration of Intra pulpal anaesthesia is definitely one of them ${ }^{22}$ and hence the candidates are adequately informed regarding the same.

From the above discussion it is very evident that unnecessary pain is being inflicted on the patient which requires prompt clinical intervention. Further studies are to be performed to standardize the type of nerve block that is to be administered for the particular procedure.

\section{CONCLUSIONS}

Root canal treatment is the most commonly performed endodontic procedure and the administration of proper LA and creating a painless experience for the patient is very important. The inferior alveolar nerve block alone is sufficient for a lower molar root canal treatment but the knowledge regarding the amount of LA and type of block to be administered is not documented. This is currently leading to unnecessary pain being inflicted on the patient.

Data sharing statement provided by the authors is available with the full text of this article at jemds.com.

Financial or other competing interests: None.

Disclosure forms provided by the authors are available with the full text of this article at jemds.com.

\section{REFERENCES}

[1] Rosenberg ES. A computer-controlled anesthetic delivery system in a periodontal practice: patient satisfaction and acceptance. J Esthet Restor Dent 2002;14(1):39-46.

[2] Robinson PD, Pitt Ford TR, McDonald F. Local anesthesia in dentistry. London: Reed Educational and Professional Publishing 2000.

[3] Gordon SM, Mischenko AV, Dionne RA. Long-acting local anesthetics and perioperative pain management. Dent Clin North Am 2010;54(4):611-20.

[4] Meechan JG. Supplementary routes to local anaesthesia. Int Endod J 2002;35(11):885-96.

[5] Ramazani M, Hamidi MR, Moghaddamnia AA, et al. Postendodontic pain of molars with irreversible pulpitis: a randomized clinical trial. Iran Endod J 2013;8(3):129-34.

[6] Hamedy R, Shakiba B, Fayazi S, et al. Patient-centered endodontic outcomes: a narrative review. Iran Endod J 2013;8(4):197-204.

[7] Eghbal MJ, Torabzadeh H. Review of high level endodontic research in pubmed index journals from Iran. Iran Endod J 2012;7(3):109-14.

[8] Khalil H. A basic review on the inferior alveolar nerve block techniques. Anesth Essays Res 2014;8(1):3-8.

[9] Kafalias MC, Gow-Gates GA, Saliba GJ. The Gow-Gates technique for mandibular block anesthesia. A discussion and a mathematical analysis. Anesth Prog 1987;34(4):142-9.

[10] Saxena A, Srivastava S, Agrawal A, et al. Comparison and clinical efficacy of local anesthetic solution xylocaine with and without adrenaline [1:200000] in dental extraction. Saint's Int Dent J 2015;1(2):96-100.

[11] Ketabi M, Shamami MS, Alaie M, et al. Influence of local anesthetics with or without epinephrine $1 / 80000$ on blood pressure and heart rate: a randomized double-blind experimental clinical trial. Dent Res J (Isfahan) 2012;9(4):437-40.

[12] Reader AL, Nusstein J. Local anesthesia for endodontic pain. Endod Topics 2002;3(1):14-30.

[13] von Arx T, Nakashima MJ, Lozanoff S. The face - a musculoskeletal perspective. A literature review. Swiss Dent J 2018;128(9):678-88.

[14] Jääskeläinen SK, Forssell H, Tenovuo O, et al. Difficult diagnosis of facial pain: a case report and mini-review. Scand J Pain 2010;1(4):179-83.

[15] Drum M, Reader A, Beck M. Long buccal nerve block injection pain in patients with irreversible pulpitis. Oral Surg Oral Med Oral Pathol Oral Radiol Endod 2011;112(1):e51-4.

[16] Cummings DR, Yamashita DDR, McAndrews JP. Complications of local anesthesia used in oral and maxillofacial surgery. Oral Maxillofac Surg Clin 2011;23(3):369-77.

[17] Haas DA. Localized complications from local anesthesia. J Calif Dent Assoc 1998;26(9):677-82.

[18] Foster W, Drum M, Reader A, et al. Anesthetic efficacy of buccal and lingual infiltrations of lidocaine following an inferior alveolar nerve block in mandibular posterior teeth. Anesth Prog 2007;54(4):163-9. 
[19] Matthews R, Drum M, Reader A, et al. Articaine for supplemental buccal mandibular infiltration anesthesia in patients with irreversible pulpitis when the inferior alveolar nerve block fails. J Endod 2009;35(3):343-6.

[20] Wallace JA, Michanowicz AE, Mundell RD, et al. A pilot study of the clinical problem of regionally anesthetizing the pulp of an acutely inflamed mandibular molar. Oral Surg Oral Med Oral Pathol 1985;59(5):517-21.
[21] Sorensen H, Skidmore L, Rzasa R, et al. Comparison of pulpal sodium channel density in normal teeth to diseased teeth with severe spontaneous pain. J Endod 2004;30:287.

[22] Nusstein JM, Reader A, Drum M. Local anesthesia strategies for the patient with a "hot" tooth. Dent Clin North Am 2010;54(2):237-47. 